\title{
ОТБОР И ОБУЧЕНИЕ ОБЩЕНАУЧНОЙ ЛЕКСИКЕ ПЕРЕВОДЧИКОВ В СФЕРЕ ПРОФЕССИОНАЛЬНОЙ КОММУНИКАЦИИ С ИСПОЛЬЗОВАНИЕМ ЭОП В УСЛОВИЯХ ПАНДЕМИИ COVID-19
}

\section{SELECTING AND LMS-BASED TEACHING GENERAL SCIENTIFIC VOCABULARY TO WOULD-BE TRANSLATORS IN PROFESSIONAL COMMUNICATION AMID COVID-19}

\section{O. Chernova \\ A. Litvinov \\ I. Telezhko}

Summary: The article concentrates on selecting and LMS MOODLEbased teaching general scientific vocabulary to would-be translators in professional communication amid COVID-19. The authors consider the issues of stratification and classification in science language vocabulary. The authors put forward their own classification of general scientific vocabulary based on the methodological triade by prof Nazarova T.B. and categorize all the selected vocabulary (1220 lexical items) into 12 groups. Individual words act as sampling units. The principles of selection of the general scientific vocabulary corpora are as follows: thematic, practical necessity, frequency, word combining ability, communicative value, building ability, word-formative value, and statistical neutrality.

The authors have prepared a variety of exercises to teach general scientific vocabulary using resources and elements of LMS MOODLE, which allows students to learn a huge volume of lexics in a limited time span with the benefit of linguistic, preverbal and verbal exercises, increase their motivation in learning foreign languages via individualization which boosts their academic performance.

Keywords: LMS MOODLE, general scientific vocabulary, translators in professional communication, pandemic.

\section{Чернова Оксана Евгеньевна}

К.n.н., дочент, ФГАОУ ВО «Российский университет дружбы народов», Москва

oxana-c@mail.ru

Литвинов Александр Викторович

К.п.н., дочент, ФГАОУ ВО «Российский университет дружбы народов»; ФГБОУ ВО "Московский государственный психолого-педагогический университет", Москва alisal01@yandex.ru

Тележко Ирина Владиленовна

K.n.н., дочент, ФГАОУ ВО «Российский университет дружбы народов», Москва, irina-telezhko@mail.ru

Аннотация: Статья посвящена отбору и организации обучения общенаучной лексике будущих переводчиков в сфере профессиональной коммуникации с использованием электронной образовательной платформы (ЭОП) MOODLE в условиях пандемии COVID-19. В работе рассматриваются вопросы стратификации и классификации лексики научного стиля речи. Авторы предлагают собственную классификацию общенаучной лексики, основываясь на методологической триаде Т.Б. Назаровой и делят отобранную лексику в количестве 1220 лексических единиц на 12 групп. В качестве единицы отбора выступает слово-значение. Отбор корпуса общенаучной лексики основывается на следующих принципах: тематическом, практической необходимости, частотности, сочетаемости слова, коммуникативной ценности слова, строевой способности, словообразовательной ценности, стилистической нейтральности. Для обучения общенаучной лексике авторами были разработаны разно0бразные упражнения с использованием ресурсов и элементов ЭOП MOODLE, что позволяет студентам в сжатые сроки самостоятельно осваивать большой объём лексического материала с помощью языковых, предречевых и речевых упражнений. Применение данной организации обучения приводит к росту мотивации к изучению иностранного языка у студентов за счет индивидуализации образовательного процесса, положительным образом сказывается на академической успеваемости.

Ключевые слова: ЭОП MOODLE, общенаучная лексика, переводчик в сфере профессиональной коммуникации, пандемия.

разовательные платформы (ЭОП).

Следует также отметить, что в условиях информационного общества, цифровизации и глобализации онлайн-обучение перестает играть второстепенную роль и постепенно занимает ведущие позиции в современной системе образования $[1,2,8]$.

Одной из важнейших задач в сложившихся условиях наряду с подготовкой высококачественных кадров, является сохранение и повышение мотивации студентов 
к обучению, развитие их самостоятельности и автономности, что невозможно без грамотного и методически обоснованного отбора содержания обучения, а также размещения отобранных материалов на электронной образовательной платформе в доступной и понятной каждому студенту форме, что, в свою очередь, позволяет сделать процесс обучения гибким и личностно-ориентированным $[6,11,12]$.

Для реализации данной задачи при обучении студентов неязыковых вузов, получающих дополнительную квалификацию «Переводчик в сфере профессиональной коммуникации», авторы данной статьи используют ЭOП MOODLE, обладающую широким спектром коммуникативных, учебных и административных инструментов и ресурсов. К несомненным достоинствам данной платформы относится то, что она бесплатна для компаний и организаций, в том числе образовательных. ЭОП MOODLE переведена более чем на 50 языков и поддерживает не менее 200000 пользователей одновременно. К преимуществам данной платформы также можно отнести легкость установки на сервер образовательной организации, а также возможность обновления при переходе на новые версии $[10,13,14]$.

Использование вышеупомянутой платформы, по нашему мнению, позволяет сохранить подготовку специалистов данного направления на высоком уровне, а также повышает интерес обучающихся к иностранным языкам.

Целью настоящего исследования является отбор и организация обучения общенаучной лексике на базе ЭOП MOODLE студентов неязыковых вузов, получающих дополнительную квалификацию «Переводчик в сфере профессиональной коммуникации».

\section{Материал и методы исследования}

В целях раскрытия актуальности заявленной темы нами был использован научно-теоретический анализ философской, педагогической, психологической, социологической литературы по теме исследования, а также метод сравнительного анализа.

\section{Результаты исследования и их обсужление}

На протяжении многих лет проблема содержания обучения в методике преподавания иностранных языков (ИЯ) является одной из самых насущных. Традиционно под содержанием обучения специалисты подразумевают все то, «чему следует учить учащихся» и чаще других упоминают следующие составляющие: знания, умения и навыки.

Авторы разделяют точку зрения Л.П. Меркуловой, которая выделяет лингвистический, психологический и методический компоненты [15].

Поскольку в данном исследовании рассматривается вопрос обучения общенаучной лексике будущих переводчиков в сфере профессиональной коммуникации с использованием ЭОП MOODLE в условиях пандемии COVID-19 (в исследовании приняли участие студенты 2 года обучения, которые, согласно Программе подготовки переводчиков в сфере профессиональной коммуникации (далее - Программа), только перешли от освоения общего английского языка к языку специальности, с предшествующим изучением общенаучной лексики и грамматики, присущей научному стилю речи), то нас в первую очередь интересует лингвистический компонент для отбора материала и его размещения на ЭОП MOODLE. Мы считаем, что отобранный для освоения материал необходимо представить в виде модулей в соответствии с предложенной авторами классификацией общенаучной лексики и провести его закрепление с помощью комплекса языковых, предречевых и речевых упражнений, разработанных с использованием ресурсов и элементов данной платформы.

При отборе и классификации общенаучной лексики авторы исходили из того, что в состав лексики научного стиля речи входят терминологическая, общеупотребительная и общенаучная лексика $[4,7]$.

Примерами общеупотребительной лексике являются артикли, союзы, местоимения, предлоги, вспомогательные глаголы, прилагательные и наречия. Терминологическая лексика - это совокупность терминов, отражающих систему понятий определенной науки. Общенаучная лексика используется в научных текстах всех отраслей науки и техники $[7,20]$

При отборе и классификации общенаучной лексики мы руководствовались такими критериями отнесения слова-нетермина к общенаучному слою лексики, как его функционирование в различных подъязыках науки и техники и обозначение общенаучных понятий [7].

Ученые классифицируют общенаучную лексику в соответствии с тематической организацией: 1) основные этапы научного познания (О.С. Ахманова), 2) этапы единого процесса приобретения знаний и их использования (М.М. Глушко) [9], 3) научная деятельность (А.Н. Пятницкий, Т.Н. Мальчевская) [18], 4) описание когнитивной деятельности и объектов и отношений внешнего мира (Л.Н. Смирнова)[19], 5) описание мира вещей и лексика, имеющая «антропоцентрический» характер (Н.Э. Аносова)[3].

Авторы данной статьи предлагают классификацию общенаучной лексики на основе методологической триады Т.Б. Назаровой (концептуализация, категоризация и 
приоритизация) [16]: 1) вводные и служебные слова, 2) классификация, дефиниция, 3) теории, гипотезы, 4) конференции, встречи, заседания, 5) эксперимент, открытие, изобретение, 6) практическая реализация, 7) приборы, инструменты, механизмы, 8) величины, размеры, размерность, 9) публикации, отчеты, научные статьи и работы, 10) оценка, роль, важность, значимость, 11) мыслительные процессы, 12) свойства предметов, объектов [20]

При отборе лексики необходимо определить единицы и принципы отбора, а также процедуры и источники отбора.

С нашей точки зрения, наиболее обоснованной и практически целесообразной единицей отбора является слово-значение.

Для отбора корпуса общенаучной лексики нами использовались следующие принципы: тематический, практической необходимости (или семантической ценности), частотности, сочетаемости слова, коммуникативной ценности слова, строевой способности, словообразовательной ценности и стилистической нейтральности.

В нашей работе в лексический минимум включались общенаучные слова, относящиеся к 3 и 4 категории индекса трудности слова [20]

Исходя из целей исследования, вначале мы отобрали лексику, соответствущую тематике технического профиля обучения. Были использованы словари и пособия: В.Д. Аракин. Словарь наиболее употребительных слов английского языка; Л.В. Банкевич. Словарь общенаучной лексики английского языка; А.Л. Пумпянский. Чтение и перевод английской научной и технической литературы; Н.К. Рябцева. Научная речь на английском языке. Руководство по научному изложению. Словарь оборотов и сочетаемости общенаучной лексики и др. В результате было отобрано 4500 лексических единиц (л. ед.). Далее, применяя вышеупомянутые принципы отбора лексики, данный список подвергся дополнительной обработке, и был получен словарь-минимум, насчитывающий 1220 л. ед.

При обучении общенаучной лексике на базе ЭОП MOODLE главенствующая роль отводится упражнениям.

Используя какое-либо количество упражнений при обучении ИЯ можно говорить о комплексе, подсистеме, системе упражнений для усвоения отдельных видов речевой деятельности и общей системе упражнений [17, с. 77]. Разработанные в данном исследовании упражнения представляют собой комплекс (по терминологии Е.И. Пассова), отражающий методическую характеристику автономной работы студентов в период пандемии, а так- же психологические и дидактические особенности ее организации.

В своей работе мы опираемся на классификацию упражнений, разработанную С.Ф. Шатиловым (языковые, предречевые и речевые упражнения, а также обучающие и контролирующие). В нашем исследовании были использованы упражнения всех типов.

При разработке комплекса упражнений мы учитывали сложность и степень новизны материала и возможности ЭОП MOODLE для создания упражнений. Перед каждым упражнением во всех модулях есть инструкция для студентов, что отражает компоненты мотивационнопобудительной фазы соответствующего вида речевой деятельности.

Из имеющихся элементов и ресурсов ЭОП MOODLE мы использовали элементы Опрос, Тест, Задание, Глоссарий, Форум и ресурсы Гиперссылка, Книга, Страница, Файл.

В нашем исследовании работа с новым лексическим материалом состояла из следующих этапов: ознакомление с новыми л. ед., первичное закрепление (ресурс Страница), развитие умений и навыков их использования в различных формах устной и письменной коммуникации. Из всех способов ознакомления с лексикой мы использовали перевод как наиболее адекватно отвечающий целям и задачам исследования. Для запоминания правописания и значений корпуса общенаучной лексики нами были разработаны различные типы упражнений с использованием элемента Тест.

Приведем некоторые примеры языковых упражнений:

1. Верно/неверно:

Disturbance - неисправность, помеха, нарушение - верно

- неверно

2. Выберите правильный вариант перевода:

- carry out - проводить, осуществить;

- accompany - накапливать, собирать;

- accumulate - сопровождать, сопутствовать;

3. Проверка правописания: напишите слова правильно.

Равный, одинаковый ( a, q, e, l, u -?)

Примеры предречевых упражнений:

1. Исправьте ошибку в следующих предложениях

- Different heavenly bodies which consist Galaxies are...

- President is designed for the well-being of the people who elected him for the post.

2. Прочтите текст, озаглавьте его, напишите, почему 
вы бы хотели принять участие в данном соревновании.

На этапе употребления лексических единиц для реализации коммуникативных задач используются речевые упражнения, например, такие, как:

1. Представьте, что вы ученый, которому предстоит выступить на конференции с докладом о своем изобретении/открытии. Напишите ту часть доклада, в которой рассказывается о нем, не забудьте дать определение, классификацию, описание и сферу употребления (около 100 слов).

2. Предложите свои определения терминов «дефиниция» и «классификация». На Форуме вместе с коллегами выберите лучшие, аргументируйте свою точку зрения. Внесите данные определения в Глоссарий.

Контроль приобретенных знаний, умений и навыков осуществлялся в конце каждой темы с помощью элемента Тест, вопросы которого включали в себя материал ранее изученных тем.

При определении результативности обучения мы опирались на исследование В.П. Беспалько [5]. Данные эксперимента или опытно-поисковой работы анализируются для того, чтобы получить числовые значения по формуле: $K=$ =а/п, где а - число правильно выполненных операций определенного задания, п - общее число предложенных задач, К - критерий данного уровня. Целесообразно принять критерий не ниже 0,7 (70\% задач).

В данной работе под результативностью понимается количество лексических единиц, удержанных в памяти студента по окончании одного семестра (17 недель), от общего количества предъявленных лексических единиц.

Студенты 2 курса, принявшие участие в исследовании в период пандемии 2020 г., продемонстрировали усвоение материала на уровне $87,95 \%$ (K=0,88), что сравнимо с результатами, полученными при смешанном обучении в 2015-2018 гг. $(K=0,89)$ [20].

\section{Выводы или зак^ючение}

Обучение общенаучной лексике, проведенное дистанционно на базе ЭОП MOODLE в период пандемии, наглядно продемонстрировало, что будущие переводчики в сфере профессиональной коммуникации способны за достаточно короткий срок (один семестр) усвоить большой объем общенаучной лексики, значительно повысило эффективность образовательного процесса за счет его индивидуализации, мотивировало студентов на самосовершенствование и профессиональный рост; способствовало формированию ценностного отношения к иностранному языку, нацелило на самостоятельное углубление имеющихся знаний и совершенствование навыков во всех видах речевой деятельности.

\section{ЛИТЕРАТУРА}

1. Авилова, И.А., Струкова, В.Г. Использование образовательной платформы eXe-Learning для разработки электронных образовательных ресурсов [Электронный ресурс] // Молодежный научный форум: Технические и математические науки: электр. сб. ст. по материалам XL студ. междунар. заочной науч.-практ. конф. - М.: «МЦН0». — 2016 —№ 11(40) - С. 8-12.

2. Алькова, Л.А. Формирование самообразовательной компетентности студентов вуза посредством интерактивных компьютерных технологий [Текст] : дис. ... канд. пед. наук / Л.А. Алькова. - Горно-Алтайск, 2015. - 205 с.

3. Аносова, Н.Э. Формирование переводческих навыков при обучении профессионально-ориентированному переводу / Н.Э. Аносова // Материалы XI международной конференции Языки и культуры в современном мире, Париж, 2014. С. 160-164.

4. Ахманова О.С. Глушко М.М. Функциональный стиль общенаучного языка и методы его исследования / 0.С. Ахманова, М.М. Глушко. М.: Изд-во МГУ, 1974. 179 c.

5. Беспалько, В.П. Слагаемые педагогической технологии / В.П. Беспалько. М.: Педагогика, 1989. 192 с.

6. Бехтерев, А.Н., Логинова, А.В. Использование системы дистанционного обучения «MOODLE» при обучении профессиональному иностранному языку [Текст] / А.Н. Бехтерев, А.В. Логинова // Открытое образование. -2013. - № 4 (99). - С. 91-97.

7. Борисова Л.И. Особенности семантики общенаучной лексики: Дис. ... канд. филол. наук / Л.И. Борисова. М, 1986. 351 с.

8. Габидулин, А.А. Социальные платформы и их будущее в образовательном процессе на примере цифровых кочевников: Мат-лы III междун. интернетконф. Connect Universum 24-26.05.2016

9. Глушко М.М. Лингвистические особенности современного английского общенаучного языка [Текст]: Дис. ... канд. филол. наук / М.М. Глушко. М., 1970. $278 \mathrm{c}$.

10. Государев, И.Б. Терминология электронных информационно-образовательных сред [Текст] / И.Б. Государев // Человек и образование. - 2016. - №1 (46). - С. $122-126$.

11. Груздев, А.Н. Электронно-образовательная площадка LMS MOODLE как средство мотивации студентов вуза к самостоятельной работе [Tекст] / А.Н. Груздев // Научно-методический электронный журнал «Концепт». - 2016. - Т. 19. - С. 246-250.

12. Даричева, М.В. 06 эффективности использования среды дистанционного образования Моodle в процессе обучения иностранному языку в неязыковом 
вузе [Текст] / М.В. Даричева // Проблемы развития непрерывного профессионального образования: материалы VI Международной научно-практической конференции. - Н.-Новгород: НГПУ им. К. Минина, 2012. - С. $240-243$.

13. Ковалева, А.Г., Анчугова 0.В. Типология электронных образовательных платформ для обучения иностранным языкам [Текст] / А.Г. Ковалева, 0.В. Анчугова // В мире научных открытий. - 2015. - № 11.1(71). - С. 585 - 594.

14. Колесова, Т.В. Условия эффективного использования электронной образовательной платформы MOODLE для повышения качества самостоятельной работы студентов при обучении иностранному языку [Текст] // Вестник Марийского государственного университета. Йошкар-0ла: МарГУ, 2015. - № 1 (16). - С. $19-22$.

15. Меркулова Л.П., Меркулов В.А. Формирование профессиональной мобильности специалистов технического профиля / Л.П. Меркулова, В.А. Меркулов // Сибирский педагогический журнал. - № 10. - 2011. С.284-294.

16. Назарова, Т.Б. Основные этапы в исследовании английского языка делового общения и новое в преподавании бизнес-английского / Т.Б. Назарова // В сб. Российская пиарология - 4: тренды и драйверы. Сборник научных трудов в честь профессора Л.В. Минаевой, место издания Издательство СанктПетербургского государственного экономического университета Санкт-Петербург, 2017. с. 72-77

17. Пассов, Е.И. Основы коммуникативной методики обучения иноязычному общению / Е.И. Пассов. - М.: Русский язык, 1989. - 276 с.

18. Пятницкий А.Н. Образно-схематическая наглядность в обучении общенаучной лексике английского языка студентов технических вузов (с применением компьютерной техники): Автореф. дисс. ... к. пед. н. СПб., 2000. - 16 с.

19. Смирнова Л.Н. Тематический аспект организации материала по специальности / Л.Н. Смирнова // Лингвистика и методика преподавания иностранных языков / Под ред. Е.С. Троянской и др. М.: Наука, 1976. - С. $90-99$.

20. Чернова, 0.Е. Формирование автономности будущих переводчиков в сфере профессиональной коммуникации на базе электронной образовательной платформы MOODLE: Дис. ... канд. Пед. Наук / 0.Е. Чернова. Екатеринбург. 2018. - 257 с.

(c) Чернова Оксана Евгеньевна (охаna-с@mail.ru), Литвинов Александр Викторович (alisal01@yandex.ru),

Тележко Ирина Владиленовна (irina-telezhko@mail.ru).

Журнал «Современная наука: актуальные проблемы теории и практики»

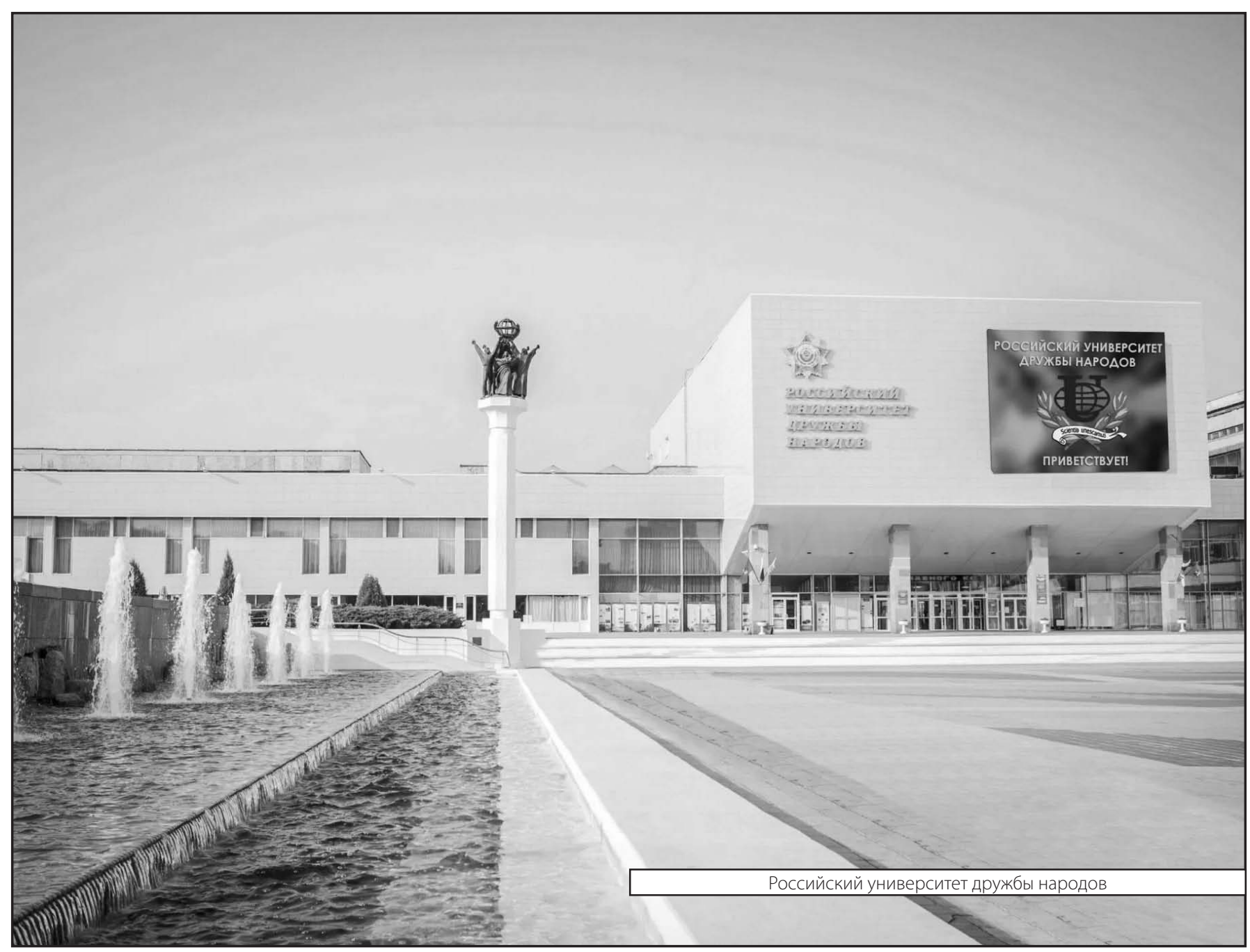

